\title{
METODOLOGÍAS ACTIVAS Y TRABAJO POR PROYECTOS: EDUCAR A TRAVÉS DEL TEATRO
}

\author{
Alejandro Canedo García \\ Universidad de León \\ acang@unileon.es \\ Deilis Ivonne Pacheco Sanz \\ Universidad de Valladolid \\ deilisivonne.pacheco@uva.es \\ Beatriz Martín Sánchez \\ Universidad de Valladolid \\ beamarsan7@hotmail.com \\ Yvet Bleye Varona \\ Universidad de Valladolid \\ yvet.b@hotmail.com \\ Ángela Gago Morate \\ Universidad de Valladolid \\ agagomorate@gmail.com
}

Recepción Artículo: 26 febrero 2020

Admisión Evaluación: 4 marzo 2020

Informe Evaluador 1: 13 marzo 2020

Informe Evaluador 2: 15 Marzo 2020

Aprobación Publicación: 20 abril 2020

\section{RESUMEN}

Educar en valores y dotar de competencias a los alumnos de Educación Primaria es un deber educativo irrenunciable. El objetivo de este trabajo es crear un programa de trasmisión de valores y adquisición de competencias a través del teatro. El fin será facilitar a maestros y tutores poder introducir y desarrollar trasversalmente los valores y competencias propuestos en la legislación vigente con una actividad altamente motivadora y reconocida cada vez más dentro del campo de las metodologías activas. Para ello justificamos legal y teóricamente los aspectos que definen la educación en valores; buscamos argumentos y evidencias que justifiquen la utilización del teatro como herramienta de introducción a la enseñanza y aprendizaje de los valores; y desarrollamos una propuesta cuya implementación permita validar este género como herramienta altamente motivadora y aglutinadora de intereses de toda la comunidad educativa. En líneas generales se ha probado que este tipo de actividades hacen que Ios alumnos se sientan protagonistas, establezcan y cumplan unas normas y compromisos que ellos mismos establecen, y el clima de aula mejore.

Palabras clave: valores; competencias; teatro; primaria; metodologías Activas

\section{ABSTRACT}

Active methodologies and project work: educate through the theater. Educating in values and providing primary school students with skills is an unavoidable educational duty. The aim of this paper is to create 


\section{METODOLOGÍAS ACTIVAS Y TRABAJO POR PROYECTOS: EDUCAR A TRAVÉS DEL TEATRO}

a programme for the conveyance of values and the acquisition of skills through theatre. The purpose will be to help teachers and tutors to introduce and develop the values and competencies proposed in the current legislation with a highly motivating activity increasingly recognized within the field of active methodologies. For this reason, we legally and theoretically justify the elements that define the Education in values; seek arguments and evidence that justify the use of the theatre as an introductory tool to the value-based teaching and learning process; and prove that the theatre is a highly motivating and unifying tool for the entire educational community throughout the the development of a proposal. In general terms, it can be observed that this activity makes students feel like protagonists, establishing and complying with rules and commitments that they themselves have set, improving the classroom climate.

Keywords: values; competencies; theatre; primary education; active methodologies

\section{ANTECEDENTES}

Nadie discute la relevancia del teatro como fenómeno social, desde las cavernas a la Grecia Clásica y hasta nuestros días. Se trata de un fenómeno sociocultural y literario fundamental, en el que se han reflejado ideas y símbolos para proporcionar respuestas a los problemas y conflictos que se plantea cada persona en el marco de la sociedad en la que vive.

El teatro y el arte en general permiten al individuo descubrir aspectos sobre los que no se había percatado de las situaciones sociales y vitales, propias y ajenas, pues, o no las ha vivido, o es el protagonista de las mismas, lo que obliga a cuestionar su objetividad.

Apunta Ortigosa (2002) que el arte, en general, acerca nuevos modos de hacer vivibles las sensaciones de dolor y de lucha, la nostalgia y la esperanza. En este mismo sentido entendemos que la producción escénica puede ayudar a descubrir e interpretar valores, encerrados en las obras de teatro.

Basta reflexionar un poco acerca del lugar que ocupa el teatro en la cultura contemporánea, para apreciar su contribución a la creación de ideas, valores y sentido en el contexto de las sociedades actuales. Cuando se ha consultado con profesionales de la dramática (directores, actores, autores), cuáles son los valores que con más intensidad se manifiestan en el teatro contemporáneo, responden: "Ia libertad, la capacidad de dar y compartir, el contacto real con el mundo y la sociedad en que vivimos, el consumismo, la ética, el compromiso y la crítica, son valores dirigidos a "llegar ser" (Cajade, 2009).

A través del roce intencionado y la relación con la sociedad en la que se desarrolla, el teatro logra actualizar los valores de un modo único y real y los legitima en un intento por unir la ética y la estética. Coincidimos, por Io tanto, con Cajade (2009), en que el objetivo del teatro es dar a las demás herramientas conceptuales que les permitan pensar y comprender la realidad. También se recoge en este artículo aquella idea de Bourdieu (1985) que entendía el teatro como un recurso social que contribuye a la creación de un depósito de sentido de especial relevancia en las sociedades plurales.

Como se pudo apreciar, los valores que el teatro persigue hoy son absolutamente coincidentes con lo que la educación en valores, descrita y referenciada en la normativa vigente, propone. Por lo tanto, no podemos dejar pasar esta evidencia sin aprovechar las posibilidades que se nos brindan para el campo educativo, porque:

La nómina de valores que en todos los tiempos se ha hecho llegar a los jóvenes a través del teatro es incontable: Ia lealtad, la unidad, la familia, la solidaridad... El teatro no solo ha sido instrumento al servicio de los centros de enseñanza, sino que ha sido el mismo lugar de enseñanza y método de trasmisión (Fernández, 2015, p.17).

No obstante, el teatro debe entrar en la escuela manteniendo su vertiente trasgresora, buscando una comprensión del contexto global y aspirando a una humanidad igualitaria, libre y creadora (Tejerina, 2005).

El aprendizaje de los valores tiene una vinculación inexcusable con la experiencia, al no poder enseñarse sin referentes experienciales de los mismos (Ortega y Mínguez, 2001). En este sentido, el teatro y la literatura en general, se constituyen en instrumentos eficaces puesto que reproducen y nos trasportan a lugares y situaciones experimentales a las que de otra forma no podríamos aproximarnos. Ese mundo al otro lado de la cuarta pared 
es el espejo de este lado, un espejo lo suficientemente desfigurado que nos entretiene, pero, sobre todo, sin que nos demos cuenta nos enseña.

\section{METODOLOGíA}

Se desarrolló un taller con el objetivo de dotar a los maestros y maestras de un centro educativo de herramientas que les permitiesen analizar obras de teatro con sus alumnos, relacionando el mismo con la transmisión de valores. El instructor se acercó al centro para impartir el curso de formación.

El taller tuvo una duración de treinta días repartidos en seis encuentros de cincuenta y cinco minutos cada uno. Los contenidos teóricos trabajados fueron: Ios valores en la legislación vigente, los valores y cómo trasmitirlos en Educación Primaria, relación entre los valores y el teatro, y estudio de las características psicoevolutivas de los niños y niñas de 12-13 años, remarcando como quedan satisfechos a través del teatro.

Tras ello se abordaron los contenidos prácticos, aplicando el modelo y ayudados por las fichas creadas al efecto para este taller (ver Tablas 1 y 2), no sin antes realizar el visionado de una obra de Teatro para motivar al grupo de trabajo (obra de contenido social para público adulto).

Por último, tuvo lugar el visionado de la obra de Teatro especialmente pensada para el público infantil, y la creación de fichas para el alumnado.

Tabla 1. Ficha Técnica y Recursos

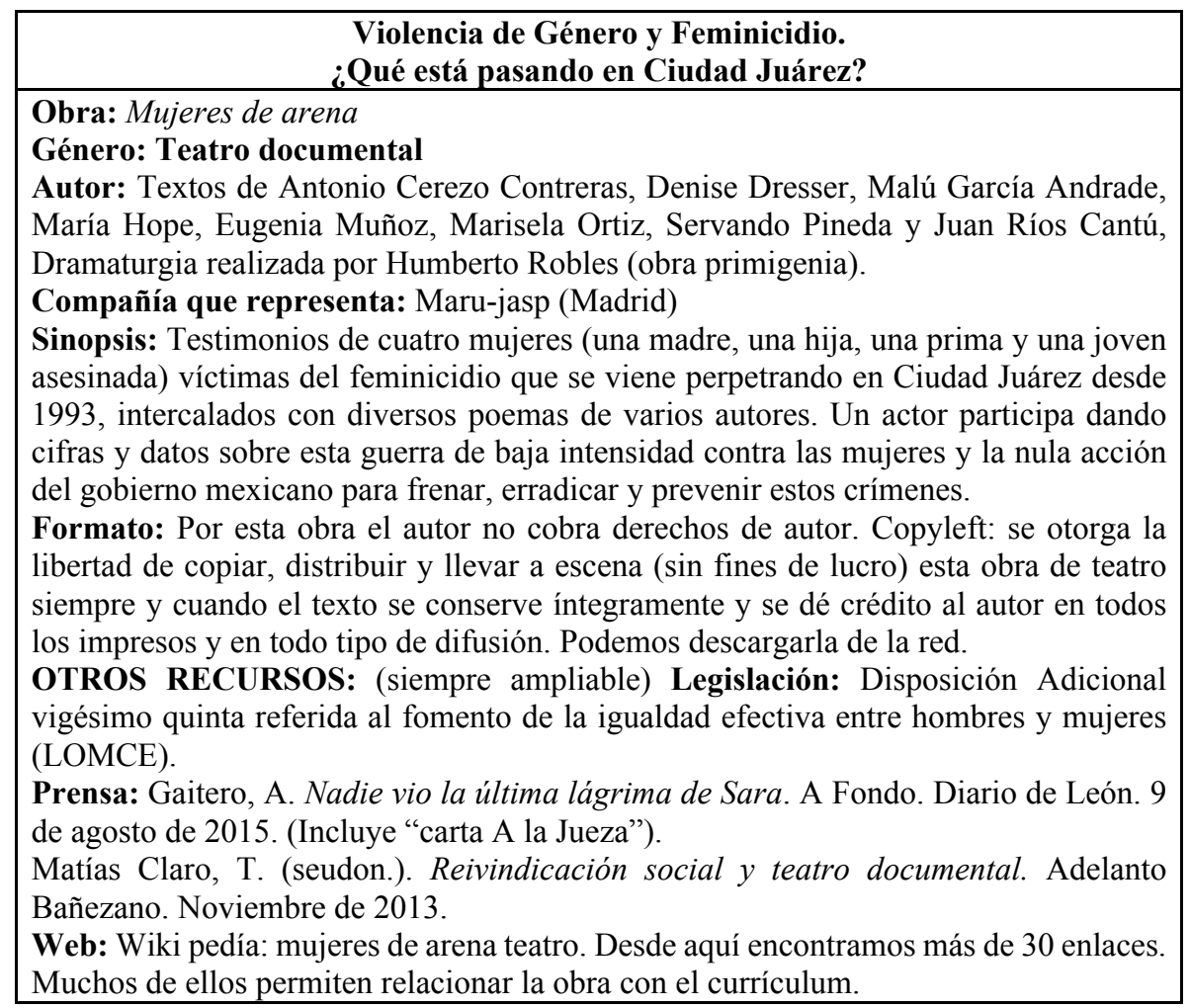

Fuente: Elaboración propia 


\section{METODOLOGÍAS ACTIVAS Y TRABAJO POR PROYECTOS: EDUCAR A TRAVÉS DEL TEATRO}

\section{RESULTADOS}

La mayor parte del profesorado se ha preguntado alguna vez sobre las posibilidades didácticas del teatro. Sin embargo, son pocos los que alguna vez han utilizado el mismo en el aula. No obstante, el teatro es una herramienta que está presente en los centros de Educación Primaria desde siempre, y, por lo tanto, requiere de un estudio y de una consideración por parte del sistema educativo desde el que no dejan de verlo como un mero recurso a modo de espectáculo al final de cada curso/trimestre.

El motivo por el que se defiende su empleo en el aula, de forma recurrente, es el hecho de que se trata de un recurso interdisciplinar, con el que los niños disfrutan y con el que se puede trabajar la expresividad oral, psicomotriz, las emociones, la autoestima, y los valores contemplados en el currículo.

En este sentido, las dificultades o limitaciones con las que se topa el teatro en el aula suelen radicar en la madurez del grupo (edad, lenguaje, etc.), la preparación previa para realizar una obra en el aula, o el hecho de que suele darse más importancia al aspecto plástico y visual, que, a aprovechar la preparación de una obra para trabajar diferentes aspectos como la literatura o el lenguaje, entre muchos otros.

Es por ello, que con este taller pretendimos acercar a los docentes un conjunto de estrategias que les permitiesen analizar junto con sus alumnos los contenidos de obras de teatro, haciendo especial hincapié en los valores que encierran.

El resultado final no podía ser más alentador, ya que ante la pregunta de si a sus alumnos/as les gustó la experiencia, que tras nuestro taller pusieron en práctica con los mismos, la mayoría de los profesores entrevistados respondió que sí.

Tabla 2. Fichas creadas

\section{Sesión 1.- Ejercicio 1}

Mujeres de Arena vs La última lágrima de Sara

Debate y recoge, en tu grupo, las conclusiones a las que llegáis respondiendo a las siguientes cuestiones.

Actividad 1.- ¿Qué mensaje trasmite la obra Mujeres de Arena? ¿Qué sensación te producen sus imágenes y sus diálogos? ¿Cómo se ha llegado a esta situación? ¿Qué podría hacerse? ¿Qué puedes haber tú?

\section{Sesión 2.- Ejercicio 1}

Actividad 2.- (Material de apoyo artículo periodístico Nadie vio la última lagrima de Sara) ¿Qué mensaje tramite el texto Nadie vio la última lágrima de Sara? ¿Qué sensación te producen estas declaraciones? ¿Cómo se ha llegado a esta situación? ¿Qué podría hacerse? ¿Qué puedes haber tú?

Ejercicio 2 (para sesiones 1 y 2)

Actividad 3.- Identifica 10 palabras clave de la obra y tradúcelas al inglés, al francés y a portugués.

Actividad 4.- Poned en común vuestro trabajo.

Actividad 5.- Presentadlo la semana que viene (en grupo) en el formato digital que elijáis.

Fuente: Elaboración propia

\section{DISCUSIÓN Y CONCLUSIONES}

El teatro y el arte en general permiten al alumno de primaria descubrir aspectos sobre los que no se había percatado en relación a determinadas situaciones sociales y vitales, propias y ajenas, pues, o no las ha vivido, 0 es el protagonista de las mismas, lo que obliga a cuestionar su objetividad. A pesar de que, en nuestra opinión, la interpretación es un hecho humano y en cierto modo espontáneo, parte de conocer cómo se crea la obra y 
todos sus elementos, lo que ha de ser guiado y aprendido en el aula para sacarle todo su potencial didáctico para el tratamiento de las competencias y los valores sociales a través de lo que los alumnos ven en escena.

\section{REFERENCIAS BIBLIOGRÁFICAS}

Ortigosa López, S. (2002). La educación en valores a través del cine y las artes. Revista Iberoamericana de Educación, 29, 157-178. ISSN-e 1681-5653

Bourdieu, P. (1985). ¿Qué significa hablar? Economía de los intercambios lingüísticos. Madrid, Akal.

Cajade Frías, S. (2009). Teatro y Valores En La Cultura Contemporánea: Un análisis desde la Antropología Social y Cultural. Prismasocial. Revista de ciencias sociales, 3.

Calderón de la Barca Fernández, V. (2015). Teatro en la enseñanza de ELE: una experiencia con alumnos japoneses. Cuadernos CANELA, 26, 40-56.

Ortega, P. y Mínguez, R. (2001). La educación moral del ciudadano de hoy. Barcelona, Paidós

Tejerina Lobo, I. (2005). Literatura infantil y formación de un nuevo maestro. Biblioteca Virtual Miguel de Cervantes, Alicante. 
